\title{
AUTORIDAD, LIBERTAD Y REPUBLICANISMO ${ }^{1}$
}

\author{
Renato Cristi \\ Wilfrid Laurier University
}

\begin{abstract}
Resumen
Este ensayo analiza la conjunción libertad/autoridad defendida por el republicanismo clásico. Como pensador moderno, Maquiavelo recupera esta síntesis clásica y define la autoridad como la condición de posibilidad de la libertad. Pero, como muestra Eric Nelson, el republicanismo de Maquiavelo es más ateniense que romano. El republicanismo de Michael Sandel tiene una orientación similar. Basado en la ontología social desarrollada por Arendt y Taylor, Sandel postula el valor intrínseco de las nociones de participación y soberanía popular. De este modo, él puede refutar la objeción de Rorty y su interpretación idiosincrática de Dewey. Según Sandel, Dewey critica el rechazo liberal de la autoridad y es capaz de articular orgánicamente la autoridad democrática y la libertad.
\end{abstract}

Palabras ClaVe: republicanismo, liberalismo, libertad, democracia, ontología social.

\section{Abstract}

This essay analyzes the conjunction freedom/authority defended by classical republicanism. As a modern thinker, Machiavelli retrieves this classical synthesis and defines the authority of law as the condition of possibility for freedom. But, as Eric Neson shows, Machiavelli's republicanism is more Athenian than Roman. Michael Sandel's democratic republicanism has a similar orientation. Besed on the social ontology developed by Arendt and Taylor, Sandel postulates the intrinsic value of the notions of participation and popular sovereignty. In this way he can refute Rorty's objections and his idiosyncratic interpretation of Dewey. According to Sandel, Dewey criticizes liberalism's rejection of authority and is able organically to articulate democratic authority and freedom.

KEY WORDS: republicanism, liberalism, freedom, democracy, social ontology.

1 Una versión anterior de este trabajo fue presentada para el programa de Clases Magistrales de la Universidad Diego Portales, el 16 de marzo de 2010, a la que fui gentilmente invitado por Vanessa Lemm y Miguel Vatter. Agradezco los comentarios de Jorge Dotti, Vanessa Lemm, Juan Ormeño, Eduardo Sabrosky y Miguel Vatter. 
$\overline{R H}$ Nuestra cultura celebra la libertad y rechaza el papel eminente que le otorgan las sociedades tradicionales a la autoridad. Buscamos por sobre todo la independencia, la espontaneidad, la autoestima, la confianza en nosotros mismo, y detestamos la dominación, la interferencia y la regimentación. ¿Por qué deberíamos aceptar reglas que nos imponen formas estrictas de control en nuestra conducta, reglas, por ejemplo, que determinan límites de velocidad en las carreteras, el uso de cinturones de seguridad en nuestros autos, reglas que restringen el uso privado o público del alcohol, el tabaco y la mariguana? ¿Si no aprobamos al delincuente que nos apunta con su pistola y roba el dinero de nuestra propiedad, por qué deberíamos aceptar que grupos de individuos, que se autodenominan 'Estado', nos amenacen con severas penas si no les entregamos la propiedad de nuestro dinero, que ellos denominan 'impuestos' o 'contribuciones'? ¿Por qué nos resulta natural aborrecer la autoridad y desconfiar profundamente de los gobiernos, los partidos políticos y en general de cualquier tipo de funcionario público? ¿Cómo poner a salvo nuestra libertad y su manifestación más concreta y diáfana, nuestra propiedad?

Los teóricos liberales responden a estos sentimientos buscando formas de avasallar y amedrentar a la autoridad, fijándole estrechos límites a su capacidad de intervenir. Anarquistas y libertarios dan un paso más allá y consideran que toda autoridad gubernativa es ilegítima y esencialmente paternalista. La existencia misma de leyes y del Estado es vista como una violación de nuestros derechos propietarios individuales. Robert Nozick, un filósofo libertario americano, que comparte el pensamiento de los anarquistas, propone una economía capitalista libre junto a un Estado mínimo cuya autoridad se reduce a proteger la libertad cuando se vea amenazada por terceros. En su libro Anarchy, State and Utopia cita con aprobación un texto de Pierre Proudhon:

Ser GOBERNADO, es ser observado, inspeccionado, espiado, dirigido, numerado, regulado, inscrito, indoctrinado, predicado, controlado, chequeado, juzgado, valorado, censurado, mandado por gente que no tiene el derecho, el conocimiento y la virtud para hacerlo. Ser GOBERNADO es, en toda operación y en toda transacción, ser anotado, registrado, numerado, gravado, estampillado, licenciado, autorizado, amonestado, tasado, prevenido, prohibido, reformado, corregido, castigado. Es, bajo el pretexto de la utilidad pública, y en el nombre del interés general, ser fiscalizado, instruido, desplumado, explotado, monopolizado, extorsionado, estrujado, engañado, robado; $\mathrm{y}$, al menor gesto de resistencia, al primer reclamo, ser reprimido, multado, vilipendiado, acosado, perseguido, aporreado, desarmado, atado, asfixiado, encarcelado, juzgado, condenado, fusilado, exiliado, sacrificado, vendido, traicionado; y como culminación de todo esto, ser burlado, ridiculizado, mofado, deshonrado. Esto es el gobierno; ésta es su justicia; ésta es su moralidad (Nozick 1974).

Junto con este intento de limitar, y aun más de abolir, toda autoridad institucional, los teóricos liberales afirman que solo el reconocimiento, la ampliación y extensión de la libertad en todas sus manifestaciones a todos los individuos puede conferir legitimidad a sus demandas y exigencias. La autoridad no tiene otra justificación, para el liberalismo, que proteger nuestra libertad, es decir, nuestra propiedad. La libertad es el universal, el paradigma último, la medida por la que juzgamos la conducta individual, y también las 
leyes y las instituciones sociales y políticas. La autoridad y la libertad parecen situarse así en los extremos opuestos del espectro social y político. Donde hay libertad no queda espacio para la autoridad; donde hay autoridad, peligra la libertad y se anuncia su extinción.

Así como la sociedad moderna mantiene una actitud de sospecha frente a la autoridad, la sociedad tradicional, en la que siempre "la praxis humana obedece a una forma u orden pre-establecidos" (Vatter 2000, p. 1), manifiesta una honda desconfianza con respecto a la libertad. Permitir a los individuos el pleno ejercicio de ella ha sido tradicionalmente visto como licencia para actuar arbitrariamente. La libertad ha sido temida como fuente de desacuerdo, como el preludio de la discordia, la contienda y la disolución social. Se concibe la libertad como algo puramente negativo, como ausencia de impedimentos. Definida así, abstracción hecha de todo contenido positivo, la libertad hace peligrar la unidad y continuidad del orden tradicional. Según Hegel, la libertad negativa abstracta es destructiva del orden y la armonía: "solo en la destrucción de algo puede esta voluntad negativa sentir y apreciar su existencia; su actualización conduce a la furia de la destrucción" (Hegel).

En las sociedades tradicionales, la autoridad, en su amplio espectro de manifestaciones sociales y políticas, tiene por función limitar, canalizar, medir y controlar la libertad. Solo la autoridad puede generar armonía y acuerdo social. En tales sociedades, los filósofos quedan a cargo de una tarea esencial: fortalecer el lazo de la unidad y asegurar los fundamentos de la autoridad. En la República, Platón escribe: “¿Puede existir un mal mayor que el desacuerdo, la dispersión y la pluralidad, ahí donde debiera reinar la unidad? ¿Puede existir un bien mayor que el vínculo de la unidad?” (República 462a7-b9).

Si miramos las cosas con más atención tenemos que conceder que ni la libertad ni la autoridad tienen un valor absoluto, que ni el anarquismo ni el autoritarismo son opciones válidas. Para que la libertad no se deteriore y se hunda en una pura negatividad, debe quedar contenida dentro de ciertos límites. ¿Cuáles serían esos límites? ¿Dónde emplazarlos? ¿Y quiénes quedarían a cargo de fijarlos e imponerlos?

Examino aquí la síntesis orgánica entre libertad y autoridad que procura el republicanismo. La compenetración de la libertas y la civitas se manifiesta en Atenas y Roma, y más tarde en las ciudades italianas del Renacimiento y los movimientos revolucionarios burgueses. En la primera sección analizo la síntesis libertad/autoridad visible en la obra de Maquiavelo, quien coincide con el republicanismo romano en concebir la autoridad de la ley como condición trascendental de la libertad. También aparece muy próximo a la tradición romana al creer posible y deseable que autoridades no democráticas puedan salvaguardar la seguridad y libertad de los individuos. La segunda sección examina la especificidad del republicanismo ateniense que determina Eric Nelson. El hacerlo le permite detectar un giro en la adhesión de Maquiavelo al republicanismo romano, pues no concurre con la generalizada condena de Roma con respecto a las leyes agrarias. Cuando afirma que "las repúblicas bien ordenadas deben tener un Estado rico y ciudadanos pobres", Maquiavelo adopta una concepción ateniense de la propiedad (Maquiavelo, 1952, p. 462). Tercero, examino las dos versiones 
encontradas del republicanismo, el ateniense y el romano, en la obra de sus respectivos apologistas contemporáneos, Philip Pettit y Michael Sandel. El tema de la participación democrática es el foco de esta discusión. En la cuarta sección, estudio las condiciones para la constitución de una autoridad republicana democrática. Para Sandel, la clave en la constitución de esa autoridad es la participación ciudadana. Inspirado en Aristóteles, Arendt y Taylor, le reconoce un valor intrínseco, y no meramente instrumental a la participación. Ese valor intrínseco lo funda en una ontología social de corte comunitario. Sin ese fundamento ontológico no parece posible justificar una autoridad republicana. Quinto, la ontología social comunitaria sirve también para fundar la soberanía popular, clave de las teorías democráticas o populistas del Estado. Me parece que cuando Skinner afirma que la teoría populista tiene, hoy en día, "un interés exclusivamente histórico" (Skinner, 2009, p. 50) lo hace porque su republicanismo es romano, y, por lo tanto, no se compromete seriamente con la soberanía popular. En la última sección, doy cuenta de las objeciones que Richard Rorty dirige a Sandel, particularmente respecto a su planteamiento de una ontología social comunitaria. Rorty presenta sus objeciones basado en una lectura de Dewey como pensador liberal minimalista, es decir, a la vez anti-realista, anti-comunitario y anti-autoritario. En su respuesta, Sandel cuestiona la interpretación rortyana de Dewey y defiende un Dewey comunitario. Me parece que es posible también cuestionar el argumento anti-autoritario. Dewey critica explícitamente la impugnación de la noción de autoridad por parte del liberalismo individualista y piensa en la necesidad de articular orgánicamente autoridad y libertad.

La tradición republicana, que afirma la libertad cívica y la autoridad como su garantía, encuentra su origen en Roma, y rebrota más tarde, a partir del siglo XII, en las ciudades del norte de Italia. Cuando Maquiavelo, el primer pensador republicano de la modernidad, entra en escena en el siglo XVI, esa tradición cuenta con una práctica política bien asentada. Este es el argumento que defiende Skinner. Italia le debe más al Código de Justiniano, comentado por Azo, que a la influencia de Aristóteles (Skinner 2002, pp. 1038). Pettit coincide con Skinner y afirma explícitamente que el origen del republicanismo hay que buscarlo en Roma, y que está "particularmente asociado al nombre de Cicerón" (Pettit 1997, p. 19). El redescubrimiento de Aristóteles sirve para darle nuevo ímpetu a la defensa de esas comunidades italianas independientes, pero son los argumentos de Cicerón y Salustio los determinantes. Cuando Maquiavelo piensa la libertad, tiene en mente la libertad que goza la ciudadanía romana. En Roma, la ley es lo que fuerza a los individuos a ser libres, "obligándolos a defender su libertad" (Skinner 1990, p. 306). Es necesario, por tanto, distinguir entre el republicanismo y la tradición liberal. Esta última desconfía de la autoridad y separa estrictamente los ámbitos de la libertad y la autoridad. Skinner piensa que el republicanismo no enfatiza la protección de nuestra libertad y nuestros derechos individuales frente a la interferencia de la autoridad. Por el contrario, los pensadores republicanos no separan libertad y autoridad, y "ponen toda su fe en el poder coercitivo de la ley" como manera de asegurar nuestra libertad (ibíd., 
p. 305). Para Maquiavelo, la autoridad de la ley es la que "crea y preserva un grado de libertad individual que, en su ausencia, prontamente colapsaría para convertirse en una absoluta servidumbre" (ibíd., p. 305).

Para entender la relación que establece Maquiavelo entre libertad y autoridad hay que considerar los dos tipos de temperamentos o humores cívicos que discierne. En El Príncipe distingue entre el temperamento de aquellos que buscan la libertad con el propósito de comandar a otros, y el de aquellos que buscan la libertad para evitar ser comandados y dominados. Los primeros son los grandi, los ricos y poderosos. Los segundos constituyen la masa popular empobrecida.

En toda ciudad uno encuentra estos dos diversos temperamentos (umori), cuyo origen está en que el pueblo desea no ser comandado y dominado por los ricos (grandi), y los ricos desean comandar y dominar al pueblo (Maquiavelo 1952, p. 317).

Esta tipología le sirve a Maquiavelo para interpretar la historia política de Roma. En su Discurso sobre la primera década de Tito Livio, reitera las diferentes razones que tienen los ciudadanos para aspirar a la libertad. Algunos pocos la desean para comandar, otros, que conforman el pueblo en su gran mayoría, la desean para no ser dominados y vivir en seguridad:

[A]lgunos, en reducido número, desean la libertad para comandar; todos los demás, en su gran mayoría, la desean para vivir en seguridad. En efecto, de cualquier manera que sea gobernada una república, nunca son más de cuarenta o cincuenta ciudadanos quienes se elevan a posiciones de autoridad (Maquiavelo 1952, p. 425).

El pueblo romano no desea ser gobernado, pero tampoco está interesado en gobernar y no tiene la vista fija en la participación política. Pero éste no es el caso del pueblo ateniense. La democracia en Atenas aspira al autogobierno de la polis y para ello requiere la participación de todos los ciudadanos. En Roma, la noción republicana del autogobierno no tiene cabida. El pueblo no aspira primordialmente a la democracia sino a la seguridad de sus ciudadanos. Según Hannah Pitkin, "la plebe romana no luchó por la democracia sino por la seguridad, no luchó por el poder público sino por la seguridad privada" (citada en Pettit 1997, p. 27). Esto significa que la democracia no es ingrediente esencial de la libertad romana. Al igual que cuarenta o cincuenta ciudadanos, también un príncipe podría garantizar la seguridad que anhela una república. Maquiavelo exhorta así al príncipe moderno a considerar el período imperial que va de Nerva a Marco Aurelio, un momento en que florece la libertad individual aunque la república romana ha dejado ya de existir. Durante ese periodo conviven armónicamente la libertad de ciudadanos que se sienten seguros y la autoridad de los buenos emperadores. El modelo que Maquiavelo ofrece al príncipe moderno es el siguiente:

[El Príncipe] podrá ver en los buenos emperadores a un príncipe que vive en la más perfecta seguridad en medio de ciudadanos que viven sin incertidumbre, mientras la justicia y la paz reinan en el mundo. La autoridad del Senado es respetada, se rinden honores a la magistratura, los ciudadanos opulentos gozan 
de su riqueza en paz, la virtud es apreciada, y por doquier reina la calma y la felicidad. Consecuentemente se han extinguido toda animosidad, toda licencia, toda corrupción, toda ambición. Podrá ver un siglo de oro en que cada ciudadano es libre para expresar y defender sus opiniones (Maquiavelo 1952, pp. 411-2).

Aunque la república ya se ha extinguido, el régimen imperial que va de Nerva a Marco Aurelio preserva el ideal republicano de la autoridad y la ley. Para el republicanismo romano, el fin y propósito de la autoridad y la ley es la preservación y enriquecimiento de la libertad. Así, Cicerón puede decir: "Somos siervos de la ley para poder ser libres" (citado en Wirszubski 1960, p. 7).

La concepción negativa de la libertad que postula el republicanismo romano va aparejada con una autoridad que no requiere de la participación democrática del pueblo. Según Pettit, la influencia de Hannah Arendt ha significado fundir el ideal republicano con "una aproximación comunitaria y populista" (Pettit 1997, p. 8). El pueblo, en este caso, asume directamente su autoridad soberana para evitar la representación de sus intereses por parte del Estado. El comunitarismo concibe al pueblo "en su presencia colectiva, como el señor, y al Estado como su siervo, y sugiere que el pueblo debe confiar en representantes y oficiales públicos solo cuando sea absolutamente necesario" (ibíd., p. 8). Este republicanismo populista y comunitario contrasta, según Pettit, con la tradición romana que ve en el pueblo no al soberano, sino a quien delega una comisión de confianza. Pettit puede tomar así distancia de la democracia y aproximarse al liberalismo. Pero, al igual que Bruce Ackerman, Pettit distingue entre liberalismo y libertarianismo (ibíd., p. 9). Libertarios como Berlín, Nozick y Gauthier definen a los individuos abstractamente, como negativamente libres, independientes de todo contexto social y dotados de derechos naturales de propiedad y contrato (Ackerman 1991, pp. 29-30). Si el republicanismo se redujera a esto, piensa Pettit, la expresión "republicanismo liberal" sería contradictoria en si misma y conduciría a "la muerte del republicanismo" (Pettit 1997, p. 30).

Cicerón mismo, considerado por Skinner y Pettit como el portaestandarte del republicanismo, se encarga de refutar la idea de que el espíritu republicano es esencial y exclusivamente romano. En su De legibus, Cicerón afirma que Platón, el más grande de los filósofos, escribió un libro "acerca de la república" (cf. Nelson 2004, p. 1). De ahí deriva el título del diálogo que su discípulo Aristóteles denominó Politeia. De ahí deriva también el hecho que la historia haya considerado a Platón como republicano a pesar de que "nunca escuchó hablar de ese término" (ibíd., p. 1). La idea de unir la tradición republicana en un solo bloque, y que ha tenido por resultado ocultar la especificidad del pensamiento griego, ha sido cuestionada por Eric Nelson. Nelson se apoya en Hegel para demostrar que el temperamento romano está sellado, desde su mismo origen, por un temple muy diferente al ateniense. En instituciones como la familia, la administración de justicia, 
la propiedad privada y la religión misma, hay rasgos que son exclusivamente romanos. Aún durante el periodo republicano, se anuncia lo que concebimos como características esenciales del liberalismo moderno (cf. Cristi 2009, p. 260).

Para Hegel, la concepción romana de la propiedad es abstracta e inmediata en tanto que no es mediada por el reconocimiento. Se trata de una concepción que reduce los derechos personales a meros derechos reales. Por definición, un derecho real (ius in rem) no necesita de tal mediación porque se constituye por una relación posesiva directa e inmediata entre una persona y una cosa. La cosa que tomamos en posesión no es de propiedad de nadie. Los derechos personales, en cambio, surgen de relaciones entre personas y presuponen un sistema original de apropiación, al interior del cual la cosas pertenecen a todos. Para reclamar y ejercer propiedad sobre algo, deben existir acuerdos que extingan los derechos propietarios existentes de otras personas e identifiquen la porción que es apropiada. Se podría decir, entonces, que el contrato precede a la propiedad, y no viceversa. Pocock confirma lo específico de la propiedad en Roma cuando se refiere al lenguaje jurisprudencial que inauguran los civilistas romanos. Para estos, la propiedad no puede concebirse como una relación entre personas, sino como "un sistema de relaciones jurídicas entre personas y cosas, o entre personas a través de las cosas" (Pocock 1979, p. 142). Esto significa que la comunidad (o el Estado) no participa en la constitución de la propiedad, sino que, en su función de mero espectador, se limita a protegerla. Hay perfecta coincidencia, de esta manera, entre lo que Cicerón y Locke piensan acerca de la propiedad. Tanto los republicanos romanos como los liberales están de acuerdo con respecto "a la inviolabilidad de la propiedad privada... y a la máxima que los gobiernos se constituyen primordialmente para preservar y proteger la propiedad de sus ciudadanos" (Nelson 2004, p. 198)².

Es precisamente en este punto donde diverge el republicanismo ateniense y se aparta del romano. Como señala Nelson, en Roma prevalece una concepción individualista de la justicia tal como la definen las Pandectas, a saber: "la justicia es la voluntad perpetua y constante de dar a cada uno lo suyo propio (ius suum)". Esto privilegia la defensa de la propiedad privada en toda su amplitud y restringe severamente, según Nelson, "el ámbito de posibles respuestas del Estado con respecto a los problemas que implican el lujo y la corrupción" (ibíd., p. 199).

También en este punto comprueba Nelson que el republicanismo romano de Maquiavelo toma un giro y se enfila hacia el ateniense. Es cierto que Maquiavelo manifiesta su desacuerdo con las leyes agrarias en Roma. Pero su desacuerdo es solo prudencial, ya que solo critica el hecho de que se promulgaran a destiempo. En cambio, en lo que respecta al valor intrínseco de la reforma agraria, se muestra de acuerdo pues

2 Según Nelson, la tradición griega que insiste "en la necesidad de emplear el poder coercitivo del Estado para mantener una distribución igualitaria de la propiedad" está poderosamente presente en el debate constitucional que tiene lugar durante la Revolución Americana (Nelson 2004, p. 199). En Chile, durante los años de la Independencia, la tradición romana es la determinante (cf. Castillo 2009). 
coincide con un sentido de justicia como igualdad. Según Maquiavelo, "las repúblicas bien ordenadas deben tener un Estado rico y ciudadanos pobres (le republiche bene ordinate hanno a tenere ricco il publico e gli loro cittadini poveri)" (Maquiavelo 1952, p. 462; cf. Nelson 2004, p. 75). Esto implica reconocerle al Estado la facultad de redistribuir la riqueza según un criterio de justicia distinto del que determina a la justicia romana. Esta última es puramente individual o conmutativa. Solo la concepción ateniense, en tanto otorga prioridad a la sociedad por sobre el individuo, puede concebir una justicia social que justifique la redistribución. Este criterio social le permite a Maquiavelo condenar la corrupción y el lujo privado como contrarios al bien de la comunidad. Solo el patrocinio público, a saber, la beneficencia que distribuye el Estado, puede quedar libre de favoritismos, amiguismos y nepotismos. Si la riqueza queda en manos privadas, y el patrocinio es distribuido por individuos opulentos, se beneficiarán solo sus favoritos inmediatos. En sus Historias Florentinas, Maquiavelo muestra reserva frente al favoritismo que puedan ejercer los grandi. Ellos tendrán la oportunidad de "proteger a los simples ciudadanos frente a la autoridad de los magistrados, podrán socorrerlos con dinero, les concederán honores inmerecidos, y captarán el favor popular brindando públicamente pan y circo" (Maquiavelo 1952, p. 1288). Maquiavelo aconseja un Estado rico y ciudadanos pobres precisamente para sofocar el germen de desigualdad que significa la existencia de los grandi, y con ello se manifiesta a favor del republicanismo ateniense.

III

La distancia que separa al republicanismo romano del ateniense se torna contemporáneamente evidente a la luz del comentario de Pettit al libro de Sandel, Democracy's Discontent. Subraya Pettit la adhesión de Sandel a lo que este denomina "versión robusta del ideal republicano" y que identifica con Aristóteles y Arendt (Sandel 1996, p. 26). Se opone así Pettit a la posibilidad de asimilar el republicanismo de Maquiavelo y Madison al modelo ateniense. Por el contrario, "lo que encontramos en Maquiavelo y Madison es un republicanismo neo-romano, de inspiración más ciceroniana que aristotélica" (Pettit 1998, p. 49). Este es el republicanismo de Tito Livio, Tácito y Polibio, quienes siempre vieron con malos ojos el énfasis participativo que adquirió la democracia en Atenas. Estos pensadores romanos nunca reconocieron el valor intrínseco de la participación. Por el contrario, privilegiaron la dispersión de la autoridad democrática en varias asambleas y la observancia estricta de la ley y el Estado de derecho. Pettit piensa que es Rousseau quien dio alas al populismo al identificar libertad y democracia participativa. Pero esto constituye una visión sesgada del republicanismo. Piensa que el verdadero republicanismo es liberal y que concibe a la autoridad democrática como un mero instrumento para asegurar la libertad, y no como su núcleo esencial (cf. Pettit 1997, p. 30).

En su réplica, Sandel reafirma su propia versión ateniense, lo que significa enfatizar el valor intrínseco de la participación como eje y fundamento de la autoridad 
democrática (Sandel 1998). Concede que en Democracy's Discontent distingue entre las dos versiones del republicanismo que apunta Pettit, pero insiste en que no opta ahí claramente por ninguna de ellas en su afán de permanecer fiel a la historia de Estados Unidos. Y ello, porque "la tradición política americana las contiene a ambas" (Sandel 1998, p. 325). Incluye la versión neo-romana que se desliga de la democracia participativa y que "concibe la virtud cívica y el servicio público como instrumentales con respecto a la libertad" (ibíd., p. 26). Al mismo tiempo, Sandel afirma que a la hora de elegir entre esas dos versiones del republicanismo se inclina por la versión ateniense, y no por el republicanismo instrumental. No sería estable una autoridad democrática que sostuviera que la participación política y la virtud cívica son únicamente un medio para que los individuos puedan satisfacer sus intereses privados. Solo una disposición ciudadana desinteresada permite promover efectivamente el bien común, alfa y omega de una autoridad democrática. Admite Sandel que su concepción republicana deriva de Aristóteles y de lo que éste concibe como la perfección propia del ser humano. La formación de una autoridad democrática, es decir, del autogobierno, presupone una serie de capacidades humanas y éstas no podrían desarrollarse en la ausencia de una ética republicana. "Deliberar en condiciones de impotencia colectiva no permite el cultivo de un sentido de responsabilidad y peso moral asociados con un genuino autogobierno" (ibíd., p. 326). Sandel reconoce que la suya es una interpretación particular del republicanismo, que se relaciona internamente con la democracia participativa y, por lo tanto, con el comunitarismo. Es necesario recuperar a Aristóteles, quien en su Política afirma que los seres humanos son esencialmente sociales, es decir, seres cuyas humanidad es función de su sociabilidad. Por ello, su participación en los asuntos públicos es esencial para el perfeccionamiento individual.

Con esto, Sandel toma distancia del republicanismo liberal que defiende Pettit. Piensa que la libertad a la que aspira el liberalismo es un valor que exige proteger a los individuos frente a la autoridad democrática. Para el liberalismo, "soy libre en la medida en que soy portador de derechos que garantizan mi inmunidad frente a decisiones mayoritarias" (Sandel 1996, pp. 25-6). Para el republicanismo ateniense, en cambio, precisamente porque asume que la libertad de los individuos se constituye en el ejercicio del autogobierno democrático, resulta redundante exigir la protección de la libertad individual frente a la autoridad gubernativa. Su definición de la libertad republicana conlleva, así, un fuerte acento comunitario: "soy libre en la medida en que soy miembro de una comunidad política que controla su propio destino y que participo en las decisiones que gobiernan sus asuntos" (ibíd., p. 26).

Sandel ha señalado que su disputa es con una determinada versión del liberalismo, el liberalismo procedimental, y no con el liberalismo como tal. En esto coincide con Taylor quien también toma distancia del liberalismo procedimental y su incapacidad de reconocer y administrar las diferencias. Lo que recomienda Taylor es un liberalismo "más complejo y multicolor" (Taylor 1998, p. 215). Según Sandel, la libertad que proclama el liberalismo procedimental no se relaciona internamente con la autoridad democrática y no demanda, por tanto, un cultivo de las virtudes cívicas. Por el contrario, exige la neutralidad del Estado en este respecto, pues no le incumbe ocuparse de la virtud o el carácter cívico de los individuos (Sandel 1996, pp. 7-8). Sandel cree posible concebir 
un liberalismo perfeccionista que no aspire a la neutralidad y busque la promoción de virtudes liberales (Sandel 1999, pp. 210-212). Además, piensa que el liberalismo procedimental se identifica con el ideal libertario de Isaiah Berlin. Para éste, la libertad liberal es negativa, mera ausencia de interferencia, y es perfectamente compatible con un régimen autoritario, "o, por lo menos, con la ausencia de autogobierno" (Sandel 1996, p. 26). Este distanciamiento de Berlin significa que el republicanismo de Sandel, más que liberal, es prioritariamente democrático.

Aunque el argumento de Sandel en Democracy's Discontent omite referencias explícitas al comunitarismo, su postura crítica frente al contractualismo supone adhesión a una ontología social comunitaria. El comunitarismo define al individuo como un ser incompleto, perfectible solo en sociedad. El individuo es un ser intersubjetivo que puede constituirse como tal solo en un contexto de relaciones sociales (Sandel 1982, pp. 62-3). El individuo debe ser visto como la parte, la sociedad como el todo, y la participación democrática como el puente que permite a la parte identificarse o integrarse al todo. A la participación debe reconocérsele, entonces, un valor intrínseco. El individuo solo puede completarse y encontrar su propia identidad en la integración participativa con el todo social. El cultivo de las virtudes cívicas tiene sentido como un modo de aproximarnos al reencuentro solidario con ese ser esencial. La ontología comunitaria se caracteriza así por un holismo social que rechaza la idea de que los individuos puedan desarrollar sus capacidades humanas en total aislamiento.

Igualmente Taylor, en consonancia con el holismo social, postula la tesis de la sociabilidad natural del ser humano según la cual los individuos no pueden desarrollar y ejercitar su capacidad de determinarse a sí mismos en ausencia de un contexto comunitario. Taylor, además, conecta estrechamente la ontología comunitaria con el republicanismo cívico. "La noción de virtud ciudadana, tal como la definen Montesquieu y Rousseau, no puede combinarse con una concepción atomista de la sociedad" (Taylor, 1989, p. 196). Tampoco puede combinarse con una concepción exclusivamente instrumentalista de la participación política. Según Taylor, "si las personas realmente se limitaran a concebir el Estado como un instrumento común, tendrían un grado nulo de patriotismo o de vertú, y el Estado sería incapaz de resistir los ataques desde el exterior o la subversión interna o la mera erosión provocada por los comportamientos antisociales" (Taylor 1988, p. 25; cf. Cristi \& Tranjan 2010).

La ontología social que funda el argumento del liberalismo contractualista se caracteriza, en cambio, por un atomismo social. Este define al individuo como un todo clausurado en sí mismo, ya completamente constituido y sin necesidad de integrarse a una totalidad superior o identificarse con ella. Si el liberalismo reconoce la existencia de lo social, se trata de una existencia convencional mediada artificialmente por el contrato. Si abandona su natural complacencia frente a la necesidad de un orden político, puede reconocerle valor a la participación, pero no como valor intrínseco sino 
puramente instrumental. La participación le sirve al individuo para reencontrarse consigo mismo, pero no es vehículo de identificación social. El cultivo de la virtud cívica no tiene un sentido comunitario, sino que significa la consolidación de la independencia y la libertad del individuo. Para el liberalismo abstracto, reconoce Taylor, un grado de mayor participación que el puramente instrumental podría ser contraproducente y aun peligroso. Contraproducente, porque permitiría que la masa ciudadana se inmiscuyera en los asuntos científicos y técnicos que requiere el arte de gobernar y esto "solo podría restarle eficacia al gobierno" (ibíd., p. 24). Peligroso, porque podría conducir a una movilización de masas y "desajustar el delicado equilibrio de la capacidad de respuesta del gobierno a una amplia gama de intereses" (ibíd., p. 24).

Todo esto significa que la autoridad democrática, por su naturaleza participativa, se conecta internamente con el comunitarismo. Un comunitarismo implícito, entonces, le permite a Sandel establecer una relación interna entre democracia y republicanismo. Resulta imposible entender la constitución de una autoridad democrática sin una referencia a las virtudes cívicas que disponen favorablemente a los individuos para participar en el autogobierno.

Es interesante notar que Pettit, quien propicia una interpretación instrumental de la participación, rechaza también el atomismo social y se manifiesta en favor de una ontología social holista. En su libro The Common Mind, Pettit demuestra la falsedad del atomismo y la viabilidad de holismo social (Pettit 1993). Concuerda así con la "tesis social" defendida por Taylor. Pero a pesar de ello, Pettit indica que la aceptación del comunitarismo involucra un rechazo de la idea de un estado neutral y un trato igualitario e indiferente con respecto a los individuos cualesquiera sean sus diferencias (ibíd., p. 286). En esta afirmación de neutralidad están implicados el ideal liberal de la tolerancia y del Estado de derecho. Es por ello que Pettit, a pesar de compartir la ontología social de Taylor y Sandel, busca distanciarse del comunitarismo, y consolidar su postura doctrinaria al interior del liberalismo. Ciertamente no al interior de un liberalismo atomista y libertario que rechaza, sino de una versión compatible con el holismo social. Para Pettit, el hecho de adherir al "holismo social" implica radicalizar el liberalismo "de una manera republicana" (Pettit 1993, p. 286). Me parece, sin embargo, que en vez de radicalizar el liberalismo de un modo republicano, esto podría relativizar el republicanismo y exponerlo al embate del contractualismo con lo que se desvirtuaría el sentido democrático del republicanismo ateniense. Hemos visto, más arriba, como el republicanismo que defiende Pettit legitima la constitución de una autoridad no democrática.

En suma, hay consenso entre republicanos neo-atenienses como Sandel y Taylor y neo-romanos como Pettit, en rechazar el atomismo y aceptar la ontología social comunitaria. Pero difieren en el valor que le asignan a la participación democrática. Sandel, en respuesta a Pettit, rechaza la posibilidad de asignarle a la democracia un valor meramente instrumental, y afirma: "a menos que los ciudadanos estimen razonablemente que la participación en el autogobierno sea intrínsecamente importante, su disposición para sacrificar intereses individuales en aras del bien común se verá erosionada por cálculos instrumentales acerca de los beneficios y costos de la participación política" (Sandel 1998, p. 325). Por su parte, los republicanos neo-romanos piensan que concederle 
valor intrínseco a la participación política no se aviene con la demanda procedimental que exige la neutralización del Estado. Se apartan así de los supuestos ontológicos que sostienen a la "tesis social" de Taylor. Con esto dejan al republicanismo a merced del liberalismo contractualista.

La ontología social comunitaria sirve también para fundar la soberanía del pueblo, es decir, la teoría populista o democrática de la autoridad estatal. En oposición a las teorías absolutistas, los republicanos del Renacimiento evocan como Roma transita de la monarquía a la república consular. Skinner menciona, a este respecto, la publicación de la primera edición completa de Tito Livio en inglés, traducida por Philemon Holland en 1600. Holland describe la expulsión de los tarquinos como "un cambio de la tiranía a "un estado libre"” (Skinner 2009, p. 18). Esto significa, comenta Skinner, que el pueblo, como cuerpo colectivo, "ya no necesitaba una cabeza”, sino que había tomado posesión de la autoridad soberana por sí mismo (ibíd., p. 18). Ese es el punto de partida para interpretaciones aun más radicales de la soberanía popular. Inspirados en discusiones escolásticas acerca del sujeto de la autoridad soberana, los republicanos ingleses afirman ahora que "los derechos de la soberanía deben permanecer siempre alojados en la universitas del pueblo" (ibíd., p. 21). Henry Parker, teórico de la causa parlamentaria en la guerra civil inglesa, niega que el monarca sea el sujeto de la autoridad soberana, como sostenía el absolutismo. "Los reyes pueden ser maior singulis, más poderosos que los individuos, pero son minor universis, de menor poder y estatus que el pueblo como un todo" (ibíd., p. 22). Concluye Parker afirmando que la autoridad soberana reside definitivamente en el pueblo.

El adversario más potente de la teoría populista es Hobbes, quien, en el Leviatán, ataca la idea de que el pueblo constituya "una unidad que puede ser considerada 'en su conjunto (considered together)"” (ibíd., p. 24). En De Cive, Hobbes todavía distingue entre pueblo (populus) y muchedumbre (multitudo) y caracteriza al pueblo como "una entidad singular con una voluntad única" a la que se le puede atribuir una acción (Hobbes 1998, p. 137). De una muchedumbre, por el contrario, no puede decirse que "posea una voluntad otorgada por la naturaleza, sino que cada persona tiene su propia voluntad. Por eso tampoco hay que atribuirle [a la muchedumbre] una acción unificada (una actio)" (ibíd., p. 76). Pero en el Leviatán, la descripción del estado natural de los seres humanos reduce al pueblo a una anárquica muchedumbre, radicalmente pluralizada e inestable. Por ello tiene razón Skinner cuando indica que para Hobbes la imagen de un "pueblo como un cuerpo unificado no tiene sentido" (Skinner 2009, p. 27). Hobbes rechaza la soberanía popular y la idea de que los monarcas soberanos tienen "menos poder" que sus súbditos "en su conjunto (all together)" (Hobbes 1968, p. 237). Solo bajo la tutela de un monarca puede constituirse un pueblo unido. En el capítulo 16 del Leviatán, Hobbes deja en claro que una muchedumbre o multitud deviene persona colectiva solo 
cuando es representada por una persona individual. Es la unidad del representante, y no la unidad del representado, lo que hace la unidad de la persona colectiva.

En forma similar, Hegel, en la Enciclopedia, concede que la finalidad del Estado es prevenir que el populus se convierta en un vulgus, en una muchedumbre carente de todo sentido de justicia, eticidad y articulación racional. Sin la unidad que impone el Estado, la sociedad se encamina de vuelta al estado de naturaleza. En tal condición, el populus deviene "un poder sin forma, salvaje y ciego como un mar agitado y elemental" (Enc §544).

No me parece, sin embargo, que Skinner tenga razón cuando concluye que la teoría populista, al igual que la absolutista, tiene, hoy en día, "un interés exclusivamente histórico" (Skinner 2009, p. 50). Puede decir esto solo porque su republicanismo es neo-romano, no se compromete con la soberanía popular, y, por tanto, no es un republicanismo esencialmente democrático. Como reconoce Taylor, los Estados democráticos se fundan en la soberanía popular. Esto significa que "para ser soberano el pueblo debe formar una entidad y tener una personalidad" (Taylor 1998, p. 220). De otra manera no podrá ni deliberar ni decidir, pues estas funciones deben ser ejercidas conjuntamente. Esto requiere un cierto grado de cohesión, porque nadie puede quedar excluido de la discusión democrática. "Un sub-grupo que no es escuchado está siendo excluido de la nación, y por esa misma razón no está obligado a obedecer la voluntad nacional" (ibíd., p. 220). Además, el diálogo ciudadano debe extenderse en el tiempo. Para que el Estado se proyecte históricamente y su legitimidad sea estable, es necesario que "sus miembros estén fuertemente comprometidos el uno con el otro y compartan una lealtad con respecto a la comunidad política" (ibíd., p. 221). En otros términos, "un estado democrático moderno requiere un pueblo que tenga una fuerte identidad colectiva" (ibíd., p. 221). Las sociedad libres no puede subsistir sin esa identidad colectiva y adicionalmente sin una confianza mutua entre los ciudadanos. Hay obligaciones públicas que todos debemos cumplir. Si no confío en que otros cumplan con sus obligaciones, es decir, si otros "no pagan sus impuestos, abusan del sistema de bienestar social, o como empleadores se benefician de un buen mercado de trabajo sin asumir ningún costo social... esta desconfianza genera gran tensión, y amenaza con deshacer toda la madeja de compromisos de la que dependen las sociedades democráticas para poder funcionar" (ibíd., p. 221). La tradición republicana sostiene que "toda sociedad política exige ciertos sacrificios y cierta disciplina por parte de sus miembros" (Taylor 1995, p. 187).

Ser libre es participar en el autogobierno, es trabajar junto con otros en la creación y defensa de los bienes comunes valorados por la comunidad política. Esta concepción se funda en la noción republicana del patriotismo que supone un fuerte sentido de identificación con la comunidad política, un lazo de solidaridad con los compatriotas y gran interés en los fines comunes de la sociedad. Esto constituye el nervio de la "tesis republicana" defendida por Taylor. La condición de un régimen de libertad es el patriotismo, la disposición a supeditar los intereses individuales al bien común. Ausente la orientación hacia el bien común como motivación determinante, solo un régimen despótico podrá "generar las disciplinas, exigir los sacrificios y las contribuciones esenciales" que una sociedad libre necesita para subsistir (ibíd., p. 193). Estas consideraciones conectan a Taylor con la teoría populista del republicanismo 
democrático y lo apartan del republicanismo neo-romano que no requiere de la formación de un pueblo como una unidad deliberativa.

Si los liberales renunciaran a su compromiso con la ontología social atomista podrían entonces entibiarse a la idea de que "una sociedad liberal procedimental puede ser republicana en importantes respectos" (Taylor 1995, p. 197). Nota esencial de una democracia republicana es que los ciudadanos estén "animados por un sentido del bien común que comparten inmediatamente" (ibíd., p. 191). En la actualidad, las sociedades occidentales perciben el constitucionalismo y el Estado de derecho como un bien común, y ello remueve un obstáculo para que el liberalismo procedimental revise sus supuestos ontológicos. Taylor concluye con una nota de esperanza: "un liberal procedimental podría aceptar el holismo; más aún, el holismo captura mucho mejor la práctica actual de las sociedades que se aproximan a este modelo" (ibíd., p. 197).

Richard Rorty rechaza la idea de apelar a argumentos ontológicos para fundar y legitimar la democracia. Aunque admite que hoy en día la metafísica es esencial para la filosofía, y que las instituciones políticas buscan una legitimación filosófica más allá de la política, reconoce con Rawls que "la necesidad de tal legitimación se irá extinguiendo gradualmente... [porque] las políticas sociales no requieren otra autoridad que un acuerdo efectivo entre los individuos" (Rorty 1988, p. 264). Postula así que su defensa de la democracia y el liberalismo "es política, y no filosófica o metafísica" (Rorty 1998, p. 118). Esto lo lleva a definir su propio liberalismo como "minimalista." Apela para ello al pragmatismo antimetafísico de Dewey, su filósofo favorito, de quien deriva su crítica a la concepción realista de la verdad como correspondencia a una realidad en sí. "Lo que más disgusta a Dewey, tanto en la epistemología realista tradicional como en las creencias religiosas tradicionales, es el temor que infunden afirmando que alguien o algo tiene autoridad sobre nosotros" (Rorty 1999, p. 7). Piensa que para Dewey es fundamental la afirmación de la libertad individual y el rechazo a la autoridad que cualquier instancia social o comunitaria pueda ejercer sobre los individuos. Apela también a Dewey para rechazar lo que Taylor y Sandel consideran ser el lado oscuro de la modernidad - la visión weberiana de un mundo secularizado y desencantado. Rorty acusa al comunitarismo de sufrir de una "nostalgia terminal" y de no ser capaz de enfrentar sin falsas expectativas la realidad moderna. Para Dewey, piensa Rorty, "el desencanto público y comunal es el precio que pagamos por la liberación espiritual, individual y privada" (Rorty 1988, p. 272-73). Perfectamente consciente del precio que es necesario pagar, Dewey se muestra dispuesto a pagarlo, y no está dispuesto a renunciar a nuestra capacidad de "dejar solas a las personas, dejar que ensayen por sí mismas sus propias concepciones de la perfección” (ibíd., p. 273). En esto estriba el antiautoritarismo de Rorty y la prioridad que le asigna a la democracia por sobre la filosofía. 
Sandel responde a las objeciones de Rorty señalando una versión minimalista del liberalismo no es en absoluto atribuible a Dewey. Por el contrario, Dewey es crítico del liberalismo individualista y lamenta la erosión comunitaria que se ha generado a partir de la modernidad. En su The Public and its Problems (1927), Dewey describe la manera como la rebelión moderna contra el feudalismo da origen a una filosofía individualista que ineptamente presenta al individuo como capaz de existir aparte e independientemente de los lazos comunitarios formativos. La idea de que los individuos se relacionan entre sí como meros individuos es profundamente errónea. Tiene sentido solo como recurso retórico dirigido en contra de estructuras feudales que obstaculizan la actividad comercial libre, y que, por tanto, son vistas como opresivas. Y tiene sentido también como efecto de la alienación social creada por las nuevas condiciones productivas. "La Gran Sociedad creada por el vapor y la electricidad podrá ser una sociedad, pero no es una comunidad" (Dewey 1927, p. 296). Según Dewey, la lucha emancipadora antifeudal "se identificó con la libertad del individuo como tal; en la intensidad de la lucha, asociaciones e instituciones fueron condenadas a granel como enemigas de la libertad salvo que fuesen percibidas como productos de acuerdos personales y la libre elección" (ibíd., p. 297). El resultado es previsible. Lo que Dewey denomina la Gran Sociedad "ha invadido y desintegrado parcialmente las pequeñas comunidades de tiempos pretéritos" (ibíd., p. 314). Este efecto social disolvente ha dejado sin efecto la posibilidad de que el gobierno pueda intervenir para crear las condiciones que permitan la existencia de "un público inclusivo y asociado fraternalmente" (ibíd., p. 303). Es claro para Sandel que Rorty tiene una lectura sesgada de Dewey.

La crítica de Dewey al liberalismo individualista busca restaurar el papel que tiene la autoridad estatal en la creación de una sociedad comunitaria. Esto queda en evidencia en el ensayo que presenta como homenaje al tricentenario de la Universidad de Harvard en 1935 y que titula “Authority and Social Change" (Dewey 1936). Defiende aquí los presupuestos teóricos del New Deal de Roosevelt y critica al liberalismo de la Gilded Age, época de mínima regulación estatal, bajos impuestos y drástica reducción del Estado de bienestar. Para ello examina el nacimiento de la libertad moderna, la sublevación generalizada en contra de la autoridad, y el desarrollo de una filosofía social que es "crítica de la idea de control por parte de la autoridad" (ibíd., p. 130). Esta filosofía, "que reclama para sí el comprehensivo título de liberalismo" (ibíd., p. 136), postula la estricta separación de las esferas de la libertad y la autoridad, y rechaza la tendencia de la autoridad a invadir la esfera propia de la libertad. Podrían evitarse la opresión y la tiranía si se denunciara a la autoridad como enemiga de la libertad. Dewey piensa que todo esto constituye un error. El problema real tiene que ver con la relación, no con la separación, de estas nociones. Así, en 1929, Dewey reconoce que “...la relación de la individualidad a la colectividad, de la libertad a la ley y la autoridad es y siempre ha sido una cuestión central para el pensamiento social y político" (Dewey 1929, p. 174).

La libertad y la autoridad, al igual que la estabilidad y el cambio, forman "una unión íntima y orgánica” (Dewey 1936, p. 131). El liberalismo está en lo correcto cuando muestra la manera como la autoridad, en su decurso histórico se ha transformado en una constricción puramente externa y hostil a la iniciativa y la innovación. Pero, al mismo tiempo, el liberalismo ha generado gran confusión al denunciar y negar "la 
importancia orgánica de cualquier manifestación de autoridad y control social" (ibíd., p. 132). Este estado de cosas define para Dewey la crisis del liberalismo contemporáneo. La solución que propone es la "interpenetración" de la libertad y la autoridad (ibíd., p. 137). La autoridad no debe paralizar sino encauzar y dirigir el cambio. Y la libertad debe ser compartida por todos y no solo por unos pocos individuos. Si esta solución ha de alcanzarse, debería ser posible medir el impacto que la filosofía del liberalismo individualista ha tenido en la industria y el comercio. Esa filosofía postula que todos se benefician cuando a los individuos se les permite la libertad de perseguir su propia ganancia. La verdad es que la iniciativa individual está determinada por los frutos de la cooperación colectiva.

Sandel observa que en The Public and its Problems, Dewey culpa al liberalismo individualista de erigir obstáculos insalvables para la práctica del autogobierno (cf. Sandel 1998, pp. 322-3). Reconoce que la historia demuestra que la libertad y el cambio no pueden ser suprimidos. El principio de la libertad que defiende el liberalismo está profundamente enraizado en los seres humanos. Pero el liberalismo lo ha entendido mal. Al mismo tiempo, quienes se opongan a este principio e intenten imponer una autoridad externa con el fin de alcanzar estabilidad y solidaridad están condenados al fracaso. Dewey explícitamente reconoce que su críticas al liberalismo laissez faire no significan "un argumento en favor del control social por medio de una economía planificada colectivamente" (Dewey 1936). No busca el predominio de la libertad sobre la autoridad, ni el predominio de la autoridad sobre la libertad, sino su relación armónica.

El problema real es la relación entre autoridad y libertad. Y este problema se oculta, y su solución se soslaya, cuando se introduce la idea que las esferas en que operan están separadas... El problema que requiere constante vigilancia es la relación íntima y orgánica entre la autoridad y la libertad, la estabilidad y el cambio (Dewey 1936).

\section{Coda}

La relación interna que concibe Dewey entre autoridad y libertad la concibe también Friedrich Engels. En diciembre de 1873, publica un breve ensayo que titula "Dell'autorità" en el Almanacco Republicano, un periódico italiano editado, en Lodi, por Enrico Bignami (Engels 1873). Este texto ilustra su rechazo de aquellos socialistas que repudian el principio de autoridad y se han plegado al movimiento anarquista. Engels sugiere que el modo de producción moderno ha dejado atrás la acción de individuos aislados y demanda su acción concertada. Para que haya concertación es necesario organizarse, lo que a su vez no resulta posible sin un reconocimiento del principio de autoridad. Engels ilustra el punto señalando que el funcionamiento de la industria textil, del sistema ferroviario y de la navegación de alta mar no sería posible sin la obediencia y subordinación de todos a la autoridad de una persona. Escribe Engels: "Querer abolir la autoridad en la gran industria, es querer abolir la industria misma, es querer destruir las fábricas de hilados a vapor para volver a la rueca" (Engels 1873). Por ello mismo, concluye que: 
[es] absurdo considerar al principio de autoridad como un principio absolutamente perverso, y el principio de la libertad como un principio absolutamente bueno. La autoridad y la libertad son nociones relativas, cuyas esferas varían en las diferentes fases del desarrollo social" (ibíd.).

José Antonio Primo de Rivera, al otro extremo del espectro político, también busca conciliar libertad y autoridad. Para este líder del falangismo español, "no existe la libertad sino dentro de un orden" (Primo de Rivera 1973, p. 426); y también afirma: "Solo se respeta la libertad del hombre cuando se le estima como... portador de valores eternos.... Solo cuando al hombre se le considera así se puede decir que se respeta de veras su libertad, y más todavía si esa libertad se conjuga... en un sistema de autoridad, de jerarquía y de orden" (ibíd., p. 67). La libertad queda vagamente definida por el reconocimiento del individuo como "portador de valores eternos" (ibíd., p. 425). En cuanto al "sistema de autoridad, jerarquía y orden" que concibe, propone un Estado total, integral y autoritario que opera de acuerdo a los lineamientos corporativistas, es decir, sin partidos políticos y sin un Parlamento. El modelo que subyace a su propuesta la toma del fascismo italiano ${ }^{3}$. Jaime Guzmán, también desde el autoritarismo, toma en cuenta la relación interna entre autoridad y libertad, y afirma: "Gobierno autoritario y sociedad libre se conjugan como palancas armoniosas y equilibradas del progreso material y espiritual" (Guzmán 1978, p. 6).

Es notable cómo pensadores con concepciones tan diametralmente opuestas puedan estar de acuerdo con respecto a la relación interna entre autoridad y libertad. Si un demócrata como Dewey, un socialista como Engels y un franquista como Primo de Rivera pueden sincronizarse en ese respecto, ¿significa esto que el complejo nocional autoridad-libertad no es más una platitud sin mayor valor teórico? ¿Estamos aquí en presencia de un esquema abstracto y vacío, que puede ser llenado con cualquier contenido?

Si aplicamos un contenido republicano al esquema que propone Engels, no hay coincidencia con el republicanismo democrático porque la autoridad que Engels tiene en cuenta no opera en la esfera política, sino que queda circunscrita a la esfera de las relaciones de producción al interior de la sociedad civil. Engels propone la superación de la estructura estatal, dejando en suspenso como podría constituirse una autoridad democrática en el dominio de lo político. El caso de Primo de Rivera es exactamente el opuesto. Basta considerar su definición de la autoridad estatal que sí es política, pero no en un sentido democrático: "Nuestro Estado será un instrumento totalitario al servicio de la integridad patria. Todos los españoles participarán en él a través de su función familiar, municipal y sindical... Se abolirá implacablemente el sistema de los partidos políticos con todas sus consecuencias: sufragio inorgánico, representación por bandos en lucha y Parlamento del tipo conocido" (ibíd., p. 340).

3 En una nota para el periódico El Fascio, Primo de Rivera escribe: "El Estado fascista, que debe tanto a la firme voluntad del Duce, sobrevivirá a su inspirador, porque constituye una organización inconmovible y robusta” (Primo de Rivera 1973, p. 41). 
Esto demuestra que la relación interna que une orgánicamente a la libertad y la autoridad tiene capacidad amplia y holgada para recibir diversos contenidos. Dewey nos enseña la manera de constreñir esa capacidad para evitar falsas lecturas autoritarias. $\mathrm{Si}$ aceptamos con Dewey que ni la libertad ni la autoridad tienen un valor absoluto, y que lo significativo es su relación recíproca, esto solo puede adquirir sentido en un contexto democrático. Adhesión a la democracia nos permite afirmar simultáneamente que no puede haber libertad sin autoridad, y tampoco autoridad sin libertad ${ }^{4}$. Se podrá entonces ver que tiene razón el republicanismo romano al poner su fe en la autoridad de la ley como manera de preservar la libertad individual. Sin autoridad, como condición transcendental de su posibilidad, no puede haber libertad. Se podrá ver también que tiene razón el republicanismo democrático al proclamar que sin libertad no puede haber autoridad. Esto se funda en la convicción democrática, vislumbrada inicialmente por los parlamentaristas ingleses, que no acepta como legítima la autoridad no fundada en el consentimiento de individuos libres. Nadie debe quedar excluido de ese consentimiento. Si algún grupo al interior de una nación no es escuchado, y su participación no es permitida o tomada en cuenta, ese grupo no está obligado a obedecer y compartir los deberes y sacrificios que entraña la vida en común, porque entonces se ha roto "la relación íntima y orgánica entre la autoridad y la libertad" a la que aspira Dewey.

\section{Referencias bibliográficas}

Ackerman, Bruce (1991), We the People: I Foundations. Cambridge: Harvard University Press, 1998.

Castillo, Vasco (2009), La creación de la República: la filosofía pública en Chile 1810-1830. Santiago: LOM, 2010.

Cristi, Renato (2009), "Roma en el pensamiento de Hegel: del republicanismo and liberalismo autoritario", en Vanessa Lemm \& Juan Ormeño Karzulovic (editores), Hegel, pensador de la actualidad. Ensayos sobre la Fenomenología del Espíritu y otros textos. Santiago: Ediciones Universidad Diego Portales; pp. 259-284.

Cristi, Renato \& J Ricardo Tranjan (2010), "Charles Taylor y la democracia republicana", Revista de Ciencia Politica 30, n. 3, 599-615.

Dewey, John (1927), The Public and its Problems, en Jo Ann Boydston (ed.), The Later Works, 1925-1953, vol. 2 (1925-1927). Carbondale \& Edwardsville: Southern Illinois University Press, 1984.

4 Samuel Huntington piensa, por el contrario, que "los seres humanos pueden tener orden sin libertad, pero no pueden tener libertad sin orden. La autoridad debe existir antes que pueda ser limitada...” (Huntington 1968, p. 7). 
(1929), "Philosophy," en Jo Ann Boydston (ed.), The Later Works, 1925 1953, vol. 5. (1929-1930). Carbondale \& Edwardsville: Southern Illinois University Press, 1984; pp. 161-177.

(1936), “Authority and Social Change", en Jo Ann Boydston (ed.), The Later Works, 1925-1953, vol. 11 (1935-1937). Carbondale \& Edwardsville: Southern Illinois University Press, 1987; pp. 130-145.

Engels, Federico (1873), "Dell'autorità", en Enrico Bignami (ed.), Almanacco Republicano. Lodi: La Plebe. http://www.marxistsfr.org/italiano/marx-engels /1872/autorita.htm

Guzmán, Jaime (1978), “Caminos para la participación”, Ercilla, 22 de febrero.

Hegel, G. F. W. (1975), Principios de la Filosofía del Derecho, trad. por Juan Luis Vermal. Buenos Aires: Sudamericana.

Hobbes, Thomas (1968), Leviathan, edit. por Brough Macpherson. Harmondsworth: Penguin.

(1998), On the Citizen, edit. por Richard Tuck and Michael Silverthorne. Cambridge: Cambridge University Press.

Huntington, Samuel (1968), Political Order in Changing Societies. New Haven: Yale University Press.

Maquiavelo, Niccolo (1952), "Discours sur la première décade de Tite-Live", Oeuvres Completès. París: Gallimard.

Nelson, Eric (2004), The Greek Tradition in Republican Thought. Cambridge: Cambridge University Press.

Nozick, Robert (1974), Anarchy, State and Utopia. Nueva York: Basic Books.

Pettit, Philip (1993), The Common Mind: An Essay on Psychology, Society and Politics. New York: Oxford University Press.

(1997), Republicanism: A Theory of Freedom and Government. Oxford: Clarendon.

(1998), “Reworking Sandel's Republicanism", en Anita L. Allen \& Milton C. Reagan Jr. (eds.), Debating Democracy's Discontent: Essays on American Politics, Law and Public Philosophy. Oxford: Oxford University Press; pp. 40-59.

Pocock, J. G. A. (1979), "The Mobility of Property and the Rise of Eighteenth Century Sociology", in Anthony Parel \& Thomas Flanagan (eds.), Theories of Property: Aristotle to the Present. Waterloo: Wilfrid Laurier University Press; pp. 141-166.

Primo de Rivera, José Antonio (1973), Obras. Madrid: Almena.

Rorty, Richard (1988), "The Priority of Democracy to Philosophy”, en Merrill Peterson \& Robert Vaughan (eds.), The Virginia Statute for Religious Freedom. Cambridge: Cambridge University Press; pp. 257-82.

(1998), “A Defense of Minimalist Liberalism", en Anita L. Allen \& Milton C. Reagan, Jr. (eds.), Debating Democracy's Discontent: Essays on 
American Politics, Law and Public Philosophy. Oxford: Oxford University Press; pp. 117-125.

(1999), "Pragmatism as Anti-authoritarianism", Revue internationae de philosophie 207: 7-20.

Sandel, Michael (1982), Liberalism and the Limits of Justice. Cambridge: Cambridge University Press.

(1996), Democracy's Discontent. America in Search of a Public Philosophy. Cambridge: Belknap Press.

(1998), "Reply to Critics", en Anita L. Allen \& Milton C. Reagan, Jr. (eds.), Debating Democracy's Discontent: Essays on American Politics, Law and Public Philosophy. New York: Oxford University Press.

(1999), "Liberalism and Republicanism: Friends or Foes?: A Reply to Richard Dagger”, Review of Politics 61: 209-214.

Skinner, Quentin (1990), “The Republican Ideal of Political Liberty”, en G. Bock, Q. Skinner \& M. Viroli (eds.), Machiavelli and Republicanism. Cambridge: Cambridge University Press; pp. 293-309.

(2002), "The rediscovery of republican values", in Quentin Skinner, Visions of Politics, vol II Renaissance Virtues. Cambridge: Cambridge University Press; pp. 10-38.

(2009), Una genealogía del Estado moderno. Santiago: Universidad Adolfo Ibáñez.

Taylor, Charles (1988), "Algunas condiciones para una democracia viable", en Rodrigo Alvayay y Carlos Ruiz (eds.), Democracia y participación. Santiago: Ediciones Melquiades.

(1989), Sources of the Self. Cambridge: Harvard University Press.

(1995), "Cross-Purposes: The Liberal-Communitarian Debate", Philosophical Arguments. Cambridge: Harvard University Press; pp. 181-203. (1998), "Living with Difference", en Anita L. Allen \& Milton C. Reagan Jr. (eds.), Debating Democracy's Discontent: Essays on American Politics, Law and Public Philosophy. Oxford: Oxford University Press.

Vatter, Miguel E. (2000), Betweeen Form and Event: Machiavelli's Theory of Political Freedom. Dordrecht: Kluwer.

Wirszubski, Chaim (1960), Libertas as a Political Ideal in Rome. Cambridge: Cambridge University Press. 